\title{
Urgences
}

\section{Roger Kahn, The Boys of Summer, New York, Signet, 1972, 402 p.}

\section{Renald Bérubé}

Numéro 15, octobre 1986

Épigraphiques

URI : https://id.erudit.org/iderudit/025362ar

DOI : https://doi.org/10.7202/025362ar

Aller au sommaire du numéro

Éditeur(s)

Urgences

ISSN

0226-9554 (imprimé)

1927-3924 (numérique)

Découvrir la revue

Citer ce compte rendu

Bérubé, R. (1986). Compte rendu de [Roger Kahn, The Boys of Summer, New

York, Signet, 1972, 402 p.] Urgences, (15), 112-113.

https://doi.org/10.7202/025362ar

Ce document est protégé par la loi sur le droit d'auteur. L’utilisation des services d'Érudit (y compris la reproduction) est assujettie à sa politique d'utilisation que vous pouvez consulter en ligne.

https://apropos.erudit.org/fr/usagers/politique-dutilisation/
Cet article est diffusé et préservé par Érudit.

Érudit est un consortium interuniversitaire sans but lucratif composé de l’Université de Montréal, l'Université Laval et l'Université du Québec à Montréal. Il a pour mission la promotion et la valorisation de la recherche. https://www.erudit.org/fr/ 


\section{deliveline}

\section{Roger Kahn: The Boys of Summer, New York, Signet, (C) 1972, 402 pages.}

Vous aimez le baseball? Faudrait - et ne vous laissez surtout pas influencer par tout ce qu'on en dit, sport lent, de peu d'action et d'intérêt, où il ne se passe à peu près rien: il faut jouer le (son) match en le regardant. Alors l'esprit est toujours en éveil, calculant, analysant, spéculant - de tous les sports, a dit un commentateur, le baseball est sans doute celui qui sait le mieux récompenser qui le surveille attentivement. Fin du bref éloge.

J'ai découvert le baseball au début des années 1950, par la radio, à l'occasion des Séries Mondiales. (Plus que la rentrée scolaire, lesdites Séries, tout amateur le sait, marquent la fin de l'été et le début véritable de l'automne.) Les Dodgers, de Brooklyn alors, avant la ruée vers l'Ouest, y participaient souvent, mais toujours pour perdre contre les Yankees de New York. Ah, quand enfin ils gagneront en 1955! Le consolant et moqueur slogan brooklynien,

Wait 'till next year en deviendra This year is next year - pour se transformer, ironique, en Wait 'till last year quand à nouveau les Dodgers se feront battre par les Yankees en 1956.

Et comment, dans le Québec d'alors, ne pas appuyer de toutes ses forces les Dodgers, dont le principal club école était à Montréal, les Royaux (même si on ne pouvait lire que Royals sur l'uniforme)? Plus encore, c'êtait à Montréal, avec les Royaux (als) de 1946, que
Jackie Robinson était devenu le premier Noir à jouer dans le baseball organisé des Blancs. Bravo pour lui, pour nous, et pour l'audace des Dodgers. Il était, dorénavant, une grande vedette à Brooklyn. Mais mon idole absolue demeurait le Duke, "Snider, Docteur", comme dit Portnoy dans le roman de Roth. Fin des (trop brefs) souvenirs.

D'origine juive (comme Roth, Malamud, etc.) et ayant grandi à Brooklyn, fils d'enseignants, Roger Kahn, la vingtaine à peine entamée, a suivi (couvert?) les Dodgers pour le Herald Tribune de New York durant les années 1952 et 1953 (et vous savez déjà ou vous avez bien deviné comment, hélas, se sont terminées ces deux saisons de baseball). Vingt ans plus tard ou à peu près, ayant doublé ou presque le nombre de ses années, Kahn décide de rendre visite, comment dire, à ces anciens jeunes athlètes superbes, à ces vedettes de la scène (sportive) recyclées, passage inévitable du temps sapant les ressources physiques, en citoyens ordinaires vivant un quotidien banalisé qui se déroule dorénavant hors des projecteurs, dans un anonymat (relatif) qui, jusqu'alors, était celui de leurs spectateurs.

Book One: The Team, Book Two: The Return - tels sont les deux volets essentiels de l'oeuvre de Kahn. Et ce livre, on l'aura deviné, n'est pas qu'un livre sur le baseball, qu'un livre de plus sur "le merveilleux monde du sport"; c'est aussi, c'est surtout un superbe roman d'apprentissage, du passage d'un âge à un autre, tant pour l'auteur et son écriture que pour les (ex-)joueurs dont il parle et dont il est, de toute évidence, très proche. En filigrane, bien sûr, le cheminement de la société américaine 
entre le début des années 1950 et le début des années 1970. Livre fort soucieux de son écriture, chaleureux, passionnant, dont les personnages, avec ou sans leur troupe ambulante, leur club, les Dodgers, sont des personnes qui, chacune à leur façon, disent rêves et déceptions, ambitions et meurtrissures, leur venue au sport et au monde - et la difficulté du retour, du retour sur soi au passé comme au présent. Et si les (ex-)athlètes ont bien sûr la part belle, Carl Erskine, Gil Hodges, Clem Labine, Joe Black, Carl Furillo, Roy Campanella, Duke Snider, Pee Wee Reese, Jackie Robinson (surtout peut-être) et d'autres encore, Roger Kahn sait aussi évoquer Robert Frost, Shakespeare, et James Joyce discutant de Hamlet dans Ulysse. Vous aimez la littérature et le baseball? Lisez The Boys of Summer (qui connut, il faut le dire, un énorme succès lors de sa parution. De même que cet autre livre plus récent, Bums de Peter Golenbock publié en 1984. Les Dodgers fascinent, semble-t-il; à cause du destin particulier, voire tragique même, de certains des bums?).

Deux remarques en terminant. Duke Snider? Oui, oui, il s'agit bien de celui qui commente les matches des Expos au réseau anglais de Radio-Canada. Le titre du livre? Ce numéro d'Urgences oblige - en épigraphe au livre de Kahn, les lignes suivantes de Dylan Thomas:

I see the boys of summer in their ruin Lay the gold tithings barren,

Setting no store by harvest, freeze the soils.

Renald Bérubé

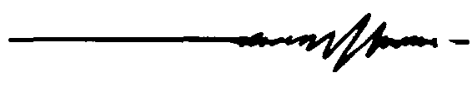

\section{Judith Thurman: Karen Blixen, Paris, Seghers (Biographie), 1986, 504 p.}

Cette excellente biographie parut d'abord en anglais sous le titre Isak Dinesen. The Life of a Storyteller en 1982. Karen Blixen? Isak Dinesen? Que l'on ne se surprenne pas, il s'agit bel et bien de la même auteure, et on pourrait continuer la liste des pseudo nymes qu'elle affectionnait tant. Pourquoi pas celui d'Osceola, nom sous lequel elle fit paraitre ses tout premiers contes (1907)? Ou encore celui de Pierre Andrézel, pseudonyme français qu'elle emprunta lors de la publication de son roman Les voies de la vengeance (1944)? Qui est donc cette femme aux multiples appellations à qui le plus récent film de Sydney Pollack, Out of Africa, semble assurer un regain de popularité? C'est précisément à cette découverte que Judith Thurman nous convie dans son magnifique ouvrage sur celle qui fut pour la littérature danoise l'équivalent de ce qu'on été Sigrid Undset pour la norvégienne et Selma Lagerlöf pour la suédoise.

Karen Blixen (pour les lecteurs français et danois) ou Isak Dinesen (pour les lecteurs anglophones) est née le 17 avril 1885 à Rungstedlund, près de Copenhague. Elle fut baptisée sous le nom de Karen Christentze Dinesen mais très tôt. dans sa famille, on l'appela "Tanne", diminutif qu'elle abhorrait et qui venait de sa prononciation enfantine de Karen. Plus tard, elle deviendra la baronne Karen Blixen-Finecke lorsqu'elle se mariera, en 1914, avec un cousin suédois, Bror Blixen-Finecke (ce dernier était un ami d'Ernest Hemingway qui le dépeignit dans un de ses textes, "The Short, Happy Life of Francis Macomber" sous les traits d'un chasseur blanc, Robert Wilson). Mariage improvisé et malheureux qui se termine par une rupture (divorce) en 1922. Puis, en 1934, elle signera sa première oeuvre importante Sept contes gothiques sous le nom d'Isak Dinesen. Ses nombreux admira. 